\title{
University teachers' perspectives on the use of mother tongue in ELT
}

\author{
Trilok Datt Tiwari \\ Assistant Professor, Far Western University, Central Campus, Mahendranagar
}

\begin{abstract}
The use of mother tongue (L1) in teaching English has always been a debatable issue as there are multiple opinions of the teachers regarding it. They are not sure to either use mother tongue in English language teaching or avoid it for effective teaching. The primary purpose of this phenomenological study of qualitative research was to find out the university teachers' perception on the use of mother tongue along with their effectiveness of L1 use at undergraduate level of Far Western University in Nepal. The participants of this study were four English language teachers teaching in the same university having more than ten years of teaching experience. The researcher used semi-structured interview and classroom observation for collecting data. The findings demonstrated that most of the teachers supported the judicious use of mother tongue in English language teaching classes based on their own experiences. The study also showed that overuse of L1 in second language (L2) classes might have some harm. It concludes that judicious use of L1 is a better way to deal with the students having poor proficiency in English language and enhance students' participation. The study recommends that teachers can make use of the students' mother tongue purposefully whenever they think it is necessary to do in their classes.
\end{abstract}

Keywords: English language teaching, perceptive, judicious use, mother tongue, second language

\section{Introduction}

The use of mother tongue (L1) in teaching English has always been a controversial issue. The English teachers throughout the world seem to be in the state of dilemma either to use it or avoid it for effective teaching. According to Sharma (2006), there are several studies which either support or oppose the use of first language in a foreign language classroom. This is the reason the teachers are confused about what to adopt in their real practice of teaching English. The supporters of mother tongue use argue that exclusion of L1 use from the classroom is impractical and likely to deprive learners of an important tool for language learning. Supporting the idea, Larsen-Freeman (2000, pp. 101-102) says, "The 
native language of the students is used in the classroom in order to enhance the security of the students, to provide the bridge from the familiar to unfamiliar and to make the meaning of the target language words clear". However, the advocates of monolingual approach go against the use of mother tongue in English language teaching classes. For example, "immersion models, the monolingual principle, and the maximum exposure hypothesis are still dominant..." (Lin, 2012a, as cited in Lin, 2013, p. 525). Ellis (1985, p.9) clearly states "It is widely acknowledged that the role of the mother tongue in foreign language learning is a negative one". Similarly, Cook (2001) also believes that L1 use cuts down exposure to the second language (L2). For them, target language should be the only medium of communication in the classroom since they believe that avoiding the use of mother tongue enhances effectiveness of teaching. However, the recent trends in second language acquisition (SLA), multilingualism and education there is reaction against the monolingual bias that takes the native speaker as the reference (Cenoz \& Gorter, 2011). Grosjean (1989) and Cook (1995) highlight qualitative difference between the mental systems of monolinguals and multilinguals (as cited in Cummin, 2007). In this regard, Auerbach (1993, p. 9) says that "L1 and/or bilingual options are not only effective but necessary for adult ESL students with limited L1 literacy or schooling and that the use of students' linguistic resources can be beneficial at all levels of ESL".

In the context of Nepal, we find teachers who follow different approaches to the use of L1 in L2 teaching. Some of them support the use of L1 whereas others reject it completely and there are some teachers who follow the middle way path, i.e. judicious use of mother tongue in English language classes. In fact, there are no unanimous views about the use of mother tongue in English language teaching. In this respect, I found several studies carried out on the same issue of mother tongue. However, the studies primarily focusing on university teachers' perspectives regarding the use of mother tongue and students' participation have not been much emphasized so far.

As an assistant professor at the Department of English Education at Far Western University, I have witnessed the problems faced by the undergraduate students learning English whose major subject is not English. I think these students have very limited knowledge of English though there are some exceptional cases. They take Compulsory English as a difficult subject to learn and pass examination. The results also prove the higher ratio of failure mainly in English. This is one of the reasons of drop out of the programme as well. The main problem I found was that the students find it very difficult to learn English due to high emphasis on English-Only 
medium of instruction. Despite the fact that English has a far and wide reach today as it is used as a lingua franca, the impact of foreign-language-only principle remains as a strong barrier for these students. Moreover, the English course books are firmly based on the foreign language only principle. They are created by native speakers of the respective language and are meant to be taught in the same language. The general assumption found among the teachers is that English-language-only as a medium of instruction is the best to achieve high level of communicative and linguistic competence in the learner. In this regard, my assumption is that English-languageonly principle is not developing the competency, but instead it is creating problems on the learners. They are discouraged to learn English as they mostly have limited knowledge of English. In fact, due to English language barrier, they are not able to properly understand English. On the other hand, the teachers and administrators are still focusing on English-language-only principle. My own experience shows that the teachers have inferiority complex if they use Nepali language in the undergraduate level class of the university. They think that they are university teachers who are far better than school teachers and if they use any other languages except English, people might tell them weak ones in subject matter. As a result, their high emphasis in English has created problems on the part of the students. Especially, the students whose major subject is not English face many problems. In fact, the reality is that majority of the students are not able to produce a single sentence in English despite the excellent marks in the exams. I believe that there is lack of participation in the class due to high emphasis on English-language-only principle. As a result of this, they are not able to develop communication skills. That's why this study attempts to explore the perspectives of the research participants on the issue of mother tongue use in English language teaching. I believe that the findings of the study may be useful for university teachers teaching English as a compulsory subject to get insights into this controversial issue and enhance students' participation in the classroom.

The following research questions were designed to frame the study under qualitative research approach:

1. How do the English teachers think about the use of mother tongue in English language teaching classes of the university?

2. Why are the students not interested in classroom interactions especially those whose major subject is different from English?

3. How do they deal with the students having poor proficiency in English? 


\section{Literature Review}

Whether or not L1 has a place in the L2 classroom has been a controversial issue for decades. Despite a growing number of research studies that have been carried out to explore the potential role of L1 in L2 teaching and learning, monolingual immersion ideologies are still dominant in many contexts all around the world (Lin, 2015). Therefore, due to these monolingual ideologies, the role and use of local indigenous languages are underestimated. Observing the context of Nepal, Phyak (2013) reveals that long history of monolingual policy and top-down policy in Nepal has affected the use of any other local languages in education. Further explaining the history, he clearly mentions that before 1990, Nepal adopted one language one-nation policy for the sake of national unity and multilingualism was thought to be a great threat but after 2006, the Ministry of Education provided space for the promotion of indigenous languages as the medium of instruction in schools. After that, English medium of instruction became the main marketing strategy of the private schools that exaggerated the myth that learning English is the yardstick for quality education promoting the English-only monolingual ideology in education and underestimating the local indigenous languages. Likewise, Awasthi (2008) observes western ideology of monolingualism which influences the use of local indigenous languages in policy making and pedagogies in Nepal. Similarly, Phyak (2015) argues that monolingual ideologies have been reproduced in Nepal by making Nepali as the national language and English as the language of global market place and technology. He claims that the reproduction of these monolingual ideologies ignores the importance of local languages and culture. By observing the gap in achievements between the students in private schools and public schools in Nepal, Giri (2011) believes that private English medium schools have developed an ideological impression on the parents that English-medium provides quality education. Therefore, most of the parents in Nepal prefer to send their children to schools where there is English-only medium of instruction. In this regard, Phyak (2011) observes that many community schools in Nepal are shifting to English medium of instruction claiming that they can also provide quality education and compete with institutional schools. These schools strictly follow English-only medium of instruction and they do not see the importance of using students' L1 as a resource in L2 teaching and learning.

Basically, there are two approaches to the use of L1 in L2 teaching based on anecdotal evidence. These two approaches are monolingual approach and bilingual approach. The followers of monolingual approach strongly believe that even a 
single word of mother tongue should not be used whereas the followers of bilingual approach seem to be skeptical about the use of L1 (Nazary, 2008). In addition to these two approaches, Nation (2003) talks about balanced approach which finds a role for the L1 but also recognizes the importance of maximizing L2 use in the classroom. In fact, there are no unanimous views about either to use mother tongue or not to use it. It has both advantages and disadvantages depending on the context. For example, Harmer (2008, as cited in Khati, 2011) points out that there are many occasions when using the students' L1 in the classroom has obvious advantages. For example, to discuss making a learning contact with their students, or to ask students what they want or need, then they will get more from lower-level students if they use the students' L1 than they try to struggle by using English. At the same time, his serious objection is over-use of the students' L1 that reduces exposure to English. Dawson (2010, as cited in Khati, 2011) accepts the fact that teachers try to control the students from using their L1 in the class, but they cannot stop them from using L1 in their brains. The students' brain space is already filed with the knowledge of L1. They try to understand the thoughts through the use of L1. That means the learners make use of their previous linguistic resources in order to understand the target language that they are learning.

Several studies have been carried out on this controversial issue of either or not mother tongue should be used in English languages classes. In his study, Khati (2011) finds out that the students mainly from government-aided schools with their poor background feel more need of L1. He conducted this study to explore the frequency and occasion of the use of mother tongue in language classroom by observing three separate classes in different schools of Nepal. He also elicited the views from two focused group discussion among teachers and students studying at the secondary level. He found that teachers generally use Nepali to explain difficult concepts, grammar rules, new words and they use it to give instructions. Khanal (2004) concluded that moderate and judicious use of mother tongue aids the learning and teaching of the target language. The teachers in the study think that it is necessary to use Nepali in the English classroom to explain difficult concepts or ideas, to practise the use of some phrases and expressions and to present complex grammar points. Similarly, Tang (2002) conducted a study among 100 students attending first-year at university in Beijing and 20 teachers to find out the attitudes of the participants towards using Chinese in the EFL classroom by using different research methods including classroom observations, interviews and questionnaires. The study found out that both the students and teachers had positive attitude towards 
the use of mother tongue in Chinese EFL context. The teachers participating in this study indicated that the translation of some words, complex ideas, even whole passage is a good way to learn foreign language. The study also showed that the teachers think Chinese should be used only when necessary to help them learn better. Likewise, Timor (2012) conducted a study to find out English teachers' attitudes and ways of implementing with regard to the use of Hebrew as the mother tongue in EFL teaching at elementary and secondary schools in Israel. This was done by conducting a study among EFL teachers and presenting their attitudes and practical implementation regarding the use of Hebrew as the mother tongue in class. Findings demonstrate that teachers' attitudes are positive and most of them see the benefit of using mother tongue in EFL teaching.From these studies, it is clear that there is rich literature in the issue of use of mother tongue in English language teaching especially focusing on school teachers and students in different contexts. However, there is a need to explore university teachers' perspective on the same issue in our context. Considering this fact, I find myself motivated to explore their perspective on the use of mother tongue. Moreover, I intend to observe how the use of students' L1 has a connection with students' participation in the classroom interaction which has not been explored yet.

\section{Methods and Procedures}

This study employed phenomenology of qualitative research. I used semistructured interview and participant observation for collecting data. Far Western University, Kanchanpur was a study area. I selected Far Western University as my research site because I myself is involved in the university as an assistant professor of English under the Department of English Education. I have witnessed and experienced of teaching English especially at central department of English education. My own involvement in the research site helped me better understand the perceptions of the research participants on the issue in the study. This is the reason why I chose Far Western University as my research site.

Gaining access to the site was not a big problem for me due to my own involvement. I had good relationship with all the faculties working there. Therefore, I had an easy access to the research site although I had to fix the convenient time with the participants for collecting information. I decided all these things in collaboration with them. I selected four teachers who were teaching English at undergraduate and graduate level for more than ten years as the study participants by using purposive sampling from the study area. The reason behind selecting the 
participants purposefully is entirely dependent on my personal judgment keeping in mind the purpose of the study. For the collection of data, I developed a flexible informal in-depth interview guideline including several open-ended questions so as to find out information to address the research questions that I posed. I also collected data from participant observation and interaction in and out of the premise of the university. I recorded the interview by using audio recording device and I also took notes during the interview. In addition, as an insider researcher, I made use of my own lived experiences of teaching and learning English as a text data. For the analysis, I transcribed the collected data. After transcribing data, I read the transcription several times to generate the clear ideas and codes. The generated codes helped me reduce the data into meaningful and manageable chunks of text. Then, I searched for common patterns by combing codes into potential themes. Moreover, I kept the common codes under a theme. After that I reviewed the themes checking if the themes work in relation to the coded extracts. Having reviewed, I developed a thematic map. Then I focused on defining the themes and identifying the essence of the themes. I crosschecked data obtained from field notes and interview to make the results more trustworthy for my research. Finally, I analyzed the themes for answering the research questions and write description of the data as part of the interpretation. I drew the conclusion from the thematic analysis.

Ethical consideration in a social research is inevitable from the beginning to the end. Therefore, my research was guided by some ethics starting from data collection process to its analysis. I regulated and maintained all the required quality and ethical standards.

\section{Results and Discussion}

The paper presents the results and discussion from the qualitative study using three main themes including using mother tongue: the force of students, using mother tongue: the best medicine and over-using mother tongue: spoil the English environment.

\section{Using Mother Tongue: The Force of Students}

The students from private and government-aided schools join the university after they complete grade 12. Generally, the students coming from private schools are relatively better than the students from government-aided schools in terms of linguistic proficiency in English. This is one of the reasons that a teacher teaching in university classes faces difficulties in dealing with these students having different level of English language skills. Therefore, totally banning L1 and using monolingual 
approach to teach English seems to be a great challenge for the teachers. To deal with the situation like this, the teachers do not seem to have unanimous opinion regarding the use of L1 in the class. There are some teachers who like the idea of using mother tongue in their class whereas there are some teachers who do not accept it.

When asked about their experiences and reasons for using mother tongue in the class to the participants who had the teaching experiences of more than ten years at the university level, the response was different: poor proficiency level of students, weak and hesitant students and difficult lessons written in foreign context. It was only when I inquired more about it that the force of students as one of the most important reasons for them to use L1 in the class was mentioned. One of the participants who taught compulsory English to the undergraduates revealed that he started using L1 because the students in his classes forced him to use it. The participant stated:

My students force me to translate some words and concept in their native language. So, as per the demand of the students I have to use mother tongue. If I reject to use LI in the class, my students don't understand. So I use it to help my students better understand (Interview vignette of Teacher 2)

Another participant started sharing his experience of using mother tongue in the class. He stated:

When I began my career as an English teacher of the university, I was against the use of mother tongue in the class. My students always wanted me to translate the lesson into their language. I found them having trouble with my English-only principle. Finally, I decided that I should use mother tongue whenever necessary and there is no harm at all. (Interview Vignette of Teacher 1)

The results of the present study on the use of mother tongue in English language teaching classes bear many similarities to Timor's (2012) study in the context of EFL teaching in elementary and secondary schools in Israel and Tang's (2002) study in Chinese EFL context. All these studies show that the teachers have positive attitude for the use of L1 in English language teaching classes. For example, teachers from China in Tang's (ibid) study and teachers from Israel in Timor's (ibid) study see more benefits of using mother tongue in English language teaching classes which support the present study carried out in the context of Far Western University in Nepal. However, the present study differs from Timor's (ibid) study in terms of 
study site. The study site of present study was university, but the study site of Timor's (ibid) was elementary and secondary schools in Israel. Similarly, the present study revealed that most of the teachers started using L1 in the class under the pressure of students as they demanded their teachers to use it. However, the participants found it useful to use in their classes. They used students' mother tongue to scaffold the learner when they faced problems as Vygotsky (1978) says that students' L1 can be used for scaffolding students' L2 acquisition.

The present study showed that the teachers have positive perceptions towards judicious use of mother tongue, although they started using students' L1 under the pressure in the beginning of their career. However, Cook ( 2001) and Ellis (1995) believe that L1 use in foreign language learning is negative one. It shows that the scholars do not have the same opinion on the issue of mother tongue.

\section{Using Mother Tongue: The Best Medicine}

Generally the students who have passed Intermediate from government-aided schools are found to have problems in English proficiency though there are some exceptional cases. These students face many problems when they join university classes. Mainly the students whose major subject is not English have to struggle a lot to cope up with compulsory English course of the university. Likewise, the teachers dealing with these students have to face several problems. Therefore, the teachers find using mother tongue is the best medicine to tackle the problem with the students having poor proficiency in English.

Using mother tongue to deal with poor proficiency level of students is the best medicine (Interview Vignette of Teacher 4)

All the participants have the experience of teaching compulsory English course to these students. In the study, most of the participants agreed that there are several benefits of using students' mother tongue in the class. They believed that benefits are more than the possible harms. Here are some common benefits that the participants explained in the interview like saving teachers' time, good way to deal with students having poor proficiency in English, encouraging students to see connection between L1 and target language and removing unnecessary worries on the part of teachers and enhance students' participation in interaction. Majority of the participants emphasized that the level of students is poor in class. The students do 
not want to participate in any interaction due to poor proficiency in English language. They believed that using students' mother tongue they can easily make the students understand the course of study prescribed by the university and enhance their participation in classroom interaction. The participants revealed that using mother tongue in English language class is not completely bad.

The study also tries to find out the perceived effectiveness of using mother tongue in English classes. Majority of the participants in the study pointed out several benefits of using mother tongue in the English class. The benefits shared by most of the teachers also bear similarities with the findings of Khanal (2004). They take mother tongue use as the best medicine to deal with students having poor proficiency in English. In fact, it is true that using students' L1, one can easily make them understand in short time without struggling a lot. My own observation of the classes also showed that L1 use in case of need in the classes seems to be promoting students' participation in the interaction. Therefore, L1 linguistic knowledge and skills can be beneficial for the development of corresponding abilities in the L2 (Cummins, 2007).

\section{Over-using Mother Tongue: Spoil the English Environment}

There are some negative things about over-using mother tongue in the class despite the support of most of the participants regarding the issue. The participants pointed out some disadvantages of using it. Most of the participants agreed that overusing mother tongue spoils English speaking environment, encourages mother tongue use, reduces opportunities to practise English and provides less exposure to target language. The class observation of one of the teachers clearly showed that there was lack of learners' participation in the classroom interaction. They were found just sitting passively in the class due to the fact that they had problems in expressing and sharing things in English language. The participant observed in the study saw more harms than benefits. He seemed strictly against the use of students' mother tongue even judiciously. He stated

I strictly oppose the use of students' mother tongue because our goal is not to teach students' native language but to develop proficiency in target language. Using mother tongue reduces exposure and opportunities on the part of the learners. As a result, they do not develop good skills in English. (Interview Vignette of Teacher 3) 
The opinion of this participant revealed that the use of mother tongue is a great hindrance from achieving goals of learning English. The points of objections revealed by the participants in the present study were like difficulty in creating English speaking environment, encouraging students to use mother tongue in English classes, reducing students' opportunities to practise English and providing less exposure to the target language. Findings of the present study support the view of Cook (2001) and Ellis (1985). They see L1 use negatively. However, Norton (2013) sees several benefits of identity investment of the learner. Therefore, she finds it necessary to develop the construct of investment to complement constructs of motivation in language. She believes that merely being motivated does not work in language acquisition unless there is identity investment of the learner. Moreover, the learners' language and culture should be valued in the classroom so that they feel they have also some kind of investment in learning. When they invest, they become highly motivated in learning language.

The study clearly shows that there are pros and cons of using Nepali in English language teaching classes. However, judicious use of mother tongue has more benefits than harm. Therefore, the study suggests that following the middle path, i.e. using mother tongue judiciously is the best way to deal with the university students having poor proficiency in target language. Moreover, it is the way to enhance students' participation in classroom interaction as well. The study result revealed that majority of teachers accepted judicious use of mother tongue when they realized that they could do better using it. The study result also shows that most of the teachers did not see any harm on using students' native language in the class.

Judicious use of mother tongue does not seem to have harm in learning English. The teachers thought that over use of mother tongue is not desirable. The mother tongue should be used if it is necessary in some occasions and the use of it should be very purposeful.

\section{Conclusion}

The present study looks at the experiences of English teachers' perception about the use of mother tongue and their perceived effectiveness of it. It also attempted to find out the way they deal with the students having poor proficiency in English. The study revealed positive perceptions of teachers towards judicious use of L1. They believed that totally banning L1 and excessively using it might not 
be a better idea. However, they tend to use L1 whenever they feel the requirement and necessity of using it in the class. They believed that using L1 helps the students understand the difficult concept and enhance participation in interaction. There are several occasions where use of L1 is proved to be a better solution to deal with the students having poor background in English. There are, of course, pros and cons of using L1 in the class, it depends on when and in which situations it is used. In fact, several studies that have been carried out in different contexts previously have supported judicious use of mother tongue and no studies recommend the excessive use of it as it reduces the opportunities to get exposed to target language. The study suggests that if L1 is used judiciously, there is no harm, but it helps develop students' participation in interaction.

The study has several limitations that should be noted. Research findings are limited to Far Western University which is located in the Far Western Region of Nepal. Similarly, the study has only used interview and participant observation to collect data for the study and it is not supplemented by learners' experience and perception. There might be mismatch between what the teachers said and what the learners actually experienced regarding the issue of mother tongue use in the English classes. However, the present study could be useful for the teachers teaching English in the universities of Nepal. They could gain insights into the controversial issue of either to use or not to use mother tongue in their classes. Similarly, the study could be helpful for the researchers who want to study about issue of mother tongue use and students' participation in university classes.

\section{References}

Auerbach, E. (1993). Reexamining English only in the ESL classroom. TESOL Quarterly, 27(1), 9-32. DOI: 10.2307/3586949

Awasthi, L. (2008). Importation of ideologies from Macaulay minutes to Wood commission. Journal of Education and Research, 1(1), 21-30.

Cenoz, J. \& Gorter, D. (2011). A holistic approach to multilingual education: Introduction. The Modern Language Journal, 95 (3), 339-343. DOI: 10.1111/ j.1540-4781.2011.01204.x

Cook, V. (2001). Using the first language in the classroom. Canadian Modern Language Review, 57(3), 402-423. DOI: 10.3138/cmlr.57.3.402 
Cummins, J. (2007). Rethinking monolingual instructional strategies in multilingual classroom. Canadian Journal of Applied Linguistics, 10(2), 221-240. Curriculum, 28(1), 74-89. Retrieved from:https:/www.researchgate.net/ publication/275636941_Conceptualizing_the_potential_role_of_L1_in_CLIL Ellis, R. (1985). Understanding second language acquisition. New York: OUP. Giri, R. A. (2011). Languages and language politics: How invisible language politics produces visible results in Nepal. Language Problems and Language Planning, 35(3), 197-221. DOI:10.1075/lplp.35.3.

Khanal, K. (2004). A study on the use of Nepali language in English classroom. An unpublished M.Ed. thesis. Kathmandu: Tribhuvan University.

Khati, A. R. (2011). When and why of mother tongue use in English classrooms. Journal of NELTA, 16(1-2), 42-51.

Larsen-Freeman, D. (2007). Techniques and principles in language teaching (2 ${ }^{\text {nd }} \mathrm{ed}$.). New Delhi: Oxford University Press.

Lin, A. M. (2015). Conceptualising the potential role of L1 in CLIL. Language, Culture and curriculum, 28(1), 74-89.

Retrieved from: https://www.researchgate.net/publication/275636941_Conceptualizing_the potential_role_of_L1_in_CLIL

Lin, A.M.Y. (2013). Towards paradigmatic change in TESOL methodologies: Building plurilingual pedagogies from the grounds up. TESOL Quarterly, 47 (3), 521-545. DOI: 10.1002/tesq. 113

Nation, P. (2003). The role of the first language in foreign language learning. The Asian EFL Journal, 5(2). Retrieved from:http://asian-efl-journal.com/ june_2003_pn.pdf

Nazary, M. (2008). The role of L1 in L2 acquisition: Attitudes of Iranian University students. Novitas- Royal, 2 (2) 138-153. Retrieved from: http://www. novitasroyal.org/nazary.pdf

Norton, B. (2013). Identity and investment in multilingual classroom. Retrieved from: http://faculty.educ.ubc.ca/norton/FLiM\%20Norton\%20Nov\%202016. pdf

Phyak, P. (2011). Beyond the facade of language planning for Nepalese primary education: Monolingual hangover, elitism and displacement of local languages? Current Issues in Language Planning, 12(2), 265-287. 
Phyak, P. (2013): Language ideologies and local languages as the medium ofinstruction policy: a critical ethnography of a multilingual school in Nepal, Current Issues in Language Planning, DOI:10.1080/14664208.2013.775557

Phyak, P.(2015). (En)Countering language ideologies: language policing in the ideospace of Facebook. Language Policy, 14 (4), pp.377-395. DOI: 10.1007/ s10993-014-9350-y.

Sharma, B. K. (2006).Mother tongue use in English classroom. Journal of NELTA, 11 (1\&2), 80-87.Retrieved from:https://www.academia.edu/962234/Mother Tongue_Use_in_English_Classroom

Tang, J. (2002). Using L1 in the English classroom. English Teaching Forum, 40 (1), 36-43. Retrieved from: https://americanenglish.state.gov/files/ae/resource files/02-40-1-h.pdf

Timor, T. (2012). Use of the mother tongue in teaching a foreign language. Language Education in Asia, 3(1). Retrieved from: http://www.leia.org/LEiA/LEiA\%20 VOLUMES/Download/LEiA_V3_I1_2012/LEiA_V3I1A02_Timor.pdf Vygotsky, L.S. (1978). Mind in society: The development of higher psychological process. Cambridge, MA: Harvard University Press. 